\title{
Documento de los teólogos latinoamericanos
}

\author{
Segunda Asamblea General \\ de la Asociación Ecuménica de Teólogos del Tercer Mundo \\ Oaxtepec, México, 7-14 de diciembre de 1986.
}

\section{Introducción}

Durante los últimos cinco años, América Latina se ha transformado en un centro de debates teologicos. Sectores significativos de las iglesias están respondiendo, con valentía evangélica, a las interpelaciones de la pobreza económica, de la opresión política y de la marginalización cultural. El evangelio es cada vez más factor de movilización social en pro de una liberación integradora de las distintas dimensiones humanas. La opción preferencial por los pobres se está concretando en los miles de comunidades eclesiales de base, en los ćrculos brblicos y en la participación de los cristianos en los procesos de cambio. Hay un considerable número de pastores que reconocen y apoyan una Iglesia en medio del pueblo, $y$ contribuyen, así, a] surgimiento de una verdadera Iglesia del pueblo de Dios con características populares. El Espíritu ha suscitado figuras proféticas de renombre mundial que confieren legitimidad y credibilidad al mensaje cristiano leído desde la perspectiva de los pobres y en contra de su pobreza. Por ello, ha habido y hay persecuciones y mártires en América Latina.

Al acompañar este proceso en el que está empeñada la Iglesia se ha visto reforzada la así llamada teologia de la liberación, cuya causa, la lucha contra el empobrecimiento del tercer mundo en su totalidad y la injusticia históricosocial, asi como los procesos de liberación conducidos por los propios oprimidos, no sólo interesa a las iglesias. Preocupa también a todas las personas que aún conservan un mínimo sentido de humanidad y de compasión ante el sufrimiento de los pobres y de los inocentes. Por esta razón, la teología de la liberación ha ganado las plazas públicas y ha llegado a ser tema de conversacion en el trabajo y hasta en el bar.

Las dos instrucciones de la Sagrada Congregación para la Doctrina de la Fe sobre "la libertad y la liberación" (la primera del 4 de septiembre de 1984 y la segunda del 22 de marzo de 1986) han suscitado debates que han ocupado y todavia ocupan el escenario de la teologia mundial. Por primera vez en la historia de América Latina, el centro del cristianismo romano-católico y muchas otras iglesias y religiones escuchan, examinan y valorizan de esta manera 
la voz de los marginados. Podemos decir que esta teologfa con sus respectivas versiones en Africa, Asia y América Latina es actualmente la reflexión más dinámica, abierta, ecuménica y fascinante de todas las iglesias. Contiene un potencial evangelizador inconmensurable pues facilita la toma de posición de cada uno ante cuestiones que son centrales en el mensaje cristiano: los pobres, su justicia y su liberación, el futuro de las víctimas de la violencia y de la opresión y la verdadera idea de Dios como Dios de vida.

En este informe queremos situar la reflexión latinoamericana dentro del contexto más amplio de la sociedad y de las distintas iglesias. Procuraremos también tener en cuenta las diversas expresiones que esta reflexión de fe adopta al verse confrontada con los desafíos especificos planteados a la conciencia cristiena. Vivimos en un tiempo de tensiones y de sufrimientos. Algunos teólogos se ven presionados y están bajo la dura vigilancia de las autoridades eclesíásticas como es el caso de Gustavo Gutiérrez en el Perú y de Leonardo Boff en el Brasil, convocado, en 1984, a Roma, para responder a un interrogatorio oficial sobre su eclesiologia pensada en el marco de la teologia de la liberación. Sin embargo, todo esto no es nada comparado con el sufrimiento del pueblo oprimido que hace aproximadamente 500 años resiste contra la dominación porque sabe que Dios está de su lado, y, a pesar de todas las dificu] tades, lucha por su liberación.

\section{DESAFIOS}

\section{Desafios políticos}

Cuatro grandes desafios políticos han caracterizado la vida latinoamericana durante los últimos cinco años. No han sido los únicos, mas su impacto ha sido tan fuerte, que, de hecho, han adquirido un carácter dominante.

En primer lugar, la preocupación por el tipo de organización democrática que los pueblos latinoamericanos quieren darse a sf mismos. Hubo un período (la década del 60 y comienzos del 70) cuando los sectores populares asociaron la palabra "democracia" a un orden institucional propio de la burguesia. Era necesario superarlo, quebrar el molde del liberalismo y de la representatividad burguesa. Lamentablemente, ante las presiones populares que buscaban esa transformación, las clases dominantes consiguieron imponer el estado de seguridad nacional, administrado por los militares, que trajo represión, mucho sufrimiento y muerte para los sectores populares. Los derechos humanos, tanto civicos como sociales, fueron violados. Las "desapariciones" y la tortura llegaron a ser cotidianas, instaurando terror, inseguridad y miedo en el pueblo. Aún se mantiene esta situación en parses como Chile, Paraguay, El Salvador, y, en menor grado, en Guatemala, Colombia y Perú. A pesar del poder que consiguieron acumular las dictaduras de seguridad nacional han ido sufriendo un proceso de desgaste que determino su carda en situa-. ciones como las de Argentina, Brasil, Uruguay, Bolivia, Perú, Guatemala, etc. En otros casos, como Haitr, también se derrocó el poder dictatorial. Esos procesos han sido resultado de una tenaz resistencia de las organizaciones 
populares, por un lado, y de la incapacidad administrativa demostrada por los militares en el poder. Como consecuencia de la acción de los movimientos populares, al no poder controlar más la situación, retornaron a los cuarteles.

En este contexto surgio la pregunta: ¿qué democracia? Si anteg ge la planteaban las clases dominantes, ahora son los sectores populares quienes la formulan. Pasada la noche de la dictaduras, ¿cómo ha de articular el pueblo un orden político que le permita abrir cauces para alcanzar mejores niveles de vida? A pesar de que ésta parecía ser la intención al volver los militares a sus posiciones normales, no se han desarrollado ni propuesto modelos para una nueva organización democrática. O sea, ha vuel to a dominar el orden burgué de tipo representativo y liberal. Sin embargo, los sectores populares quieren participar decisivamente en la historia en la que les corresponde actuar. Esto significa que han llegado a una nueva valorización de la democracia, considerada más y más como un espacio donde se pueden conjugar varios proyectos polfticos. Los grupos dominantes no acompañen esta exigencia de las clases populares, y manifiestan una clara nostalgia por el Estado de seguridad necional.

Los sectores populares procuran crear algo nuevo. En ese sentido, su acción tiene un carácter profético y el pensamiento que proyectan hacia el futuro pone de relieve el signo positivo de la utopia. Frente a esto, lo que ofrecen las clases dominantes, además de no estar a la altura de las exigencias del pueblo, posee la marca prosaica de un pragmatismo sin imaginación ni grandeza. En estas circunstancias, el desafio es ¿cómo forjar esta nueva democracia con la participación de les mayorias? Y, relacionada con ella, esta pregunta, ¿cómo construir una unidad popular que dé fuerza al movimiento del pueblo para garantizar el nacimiento y la permanencia de esa nueva democracia?

En segundo lugar, un desafio dramático de estos últimos cinco años ee conseguir una paz en Centroamérica, que permita al respeto de la soberanfa de los pueblos de esa región. La voluntad popular enfatiza la necesidad de plasmar transformaciones estructurales que aseguren justicia y libertad para todos, terminando asi con la dominación de las oligarquías apoyadas por el imperialismo. La situación en Nicaragua, asf como las luchas insurreccionales en El Salvador, Guatemala y Honduras, expresan esta realidad fundamental. A esta voluntad popular se opone la decisión del gobierno norteamericano de hacer todo lo posible para impedir que se concreten esas reformas. Asi pues, apoya la contrarrevolución que desde Honduras ataca Nicaragua y agrede de varias formas a este pars; que sostiene abiertamente al ejército de El Salvador en su acción antipopular y antidemocrática; que ha orientado y contribuido para que en Guatemala se mate y reprima a vastos sectores del pueblo; que ha tomado prácticamente posesión de Honduras, convertida actualmente en una gran base estadounidense.

El intento del pueblo de Nicaragua que procura crear una sociedad nueva se ha visto profundamente afectado por esta politica de la administración Reagan. Desde 1979, en Nicaragua, se busca plasmar un proceso de transformaciones estructurales (reforma agraria, reforma urbana, reforma de la empresa industrial, etc.) e institucionaleg (nueva constitución) con el pro- 
pósito de llegar a forjar una sociedad más justa y equitativa. Es una sociedad que se abre a la participación de las mayorías, que fueron prácticamente excluidas de los procesos de decisión durante el período de la dictadura somocista. O sea, que se asiste hoy en Nicaragua a un proceso que tiende a dar forma y peso institucional a la república de los pobres. Es una experiencia que suscita esperanzas en el resto de América Latina, pero que el gobierno de Estados Unidos esté intentando obstaculizar violentamente.

Todo esto ha significado una profunda desestabilización y grave deterioro para las sociedades centroamericanas. Es una situación de guerra abierta, que tiende a agravarse. Los pueblos de la región, tal como clamaba la multitud en Nicaragua en marzo de 1983 cuando el Papa Juan Pablo II visitó ese pars, quieren la paz. Es algo muy importante para la vida de esa gente pobre y sufrida. Sin embargo, el gobierno norteamericano mantiene su actitud imperialista, creando un verdadero foco de peturbación, dolor y muerte en esa región de América Latina. El resultado es dramático: miles de muertos, familias sacudidas por el dolor y el sufrimiento, carrera armamentista y el peligro de que una situación semejante a la que asoló Vietnam llegue a dominar en la región.

Los esfuerzos en favor de la paz desplegados por el grupo de Contadora (integrado por representantes de los gobiemos de Colombia, México, Panamá y Venezuela, y apoyado por los de Argentina, Brasil, Perú y Uruguay) han sido sistemáticamente saboteados por Estados Unidos y sus aliados centroamericanos.

La existencia de este conflicto en el hemisferio lleva a la perpetuación del militarismo que es evidente a través de la cartera de armamentos (no sólo en Centroamérica, sino en toda América) y el crecimiento de otros gastos militares que, con excepción de Argentina, han seguido aumentando en los demás parses. De este modo se refuerza la posición de los ejércitos y aumenta el peligro de que pueda volver a dominar la ideologia de seguridad nacional, que tanto daño ha causado en América Latina.

En tercer lugar, cuando se observa el proceso histórico de la región durante los últimos cinco años, hay que constatar el desafío creciente que presentan en el campo político los pueblos de las razas oprimidas. Indios y negros han sido sometidos a una dominación bárbara durante siglos. Hoy su resistencia deja de ser silenciosa para transformarse en algo organizado, militante, portador de nuevos proyectos de saciedad. Es lo que ha podido observarse en Guatemala, donde las dictaduras militares han sometido a la población indigena a matanzas sistemáticas. Es lo que se percibe en Perú, especialmente en la región de Ayacucho, donde importantes sectores indígenas se pliegan a la acción de la guerrilla. Igualmente en Nicaragua, donde el problema de la situación de los miskitos, sumus y ramas aún no se ha resuelto satisfactoriamente. Con esto no se quiere decir que haya que justificar todas y cada una de las reivindicaciones de estos grupos, sino simplemente que ellas expresan un desafio político considerable, que viene de los más pobres, de los más oprimidos, de quienes han sido dejados de lado en América Latina.

En este contexto, hay que mencionar el gravisimo hecho de la invasión a Granada, en octubre de 1983, por parte del gobierno de Estados Unidos, interrumpiendo un proceso de liberación nacional y de democracia popular. Fue una acción vergonzosa, donde se manifestó la arrogancia del grande contra el 
pequeño, la arbitrariedad imperialista y su voluntad antipopular. Fue también una clara expresión de racismo contra esa voluntad de liberación que ponen en evidencia los pueblos de las razas oprimidas.

En cuarto lugar, como hecho político nuevo cuyas consecuencias pueden ser muy grandes, es necesario indicar la creciente participación política de la mujer ( $y$, en especial, de las mujeres pobres) en América Latina. Esta tendencia, que ya se había percibido desde fines de los años 70, ha tomado mucha fuerza en el correr de los ültimos cinco años. Las mujeres demuestran muchas veces en la lucha política un valor que no siempre tienen los hombres. Y, además, una sensibilidad muy grande frente a la injusticia y la violación de los derechos humanos. Están presentes en las luchas por la liberación en El Salvador, en la defensa por Nicaragua libre, en las reivindicaciones de los "sin tierra" en Brasil, en la militancia contra la dictadura de Pinochet en Chile, en la aplicación de los derechos humanos en Argentina, etc. Esta presencia de la mujer en la vida política de Latinoamérica, además de enriquecerla, plantea desaf́os de considerable importancia. Ciertamente, la vida política latinoamericana tiene que ser menos machista y más abierta e inclusiva.

\section{Económicos}

Si en Centroamérica hay una situación de guerra abierta, si hay luchas de guerrillas en Colombia, Perú y Chile, en el resto de América Latina predomina lo que se puede llamar una situación de guerra social y economica, que en algunos casos alcanzó dimensiones devastadoras. Por ejemplo, durante los cinco años de sequia continuada en el Nordeste brasileño, murieron 3.000 .000 de personas. La falta de lluvias con sus efectos fue la circunstancia de esta tragedia, mas su verdadera causa está en las condiciones estructurales (monopolio de la tierra y de las reservas de agua) que van contra la vida del pueblo e impiden la satisfacción de sus necesidades básicas.

Es verdad que no es posible generalizar sobre la vida económica latinoamericana. Las diferencias entre los países de la región son muy grandes: el gigante Brasil está junto al pequeño Uruguay, y la sombra de México se proyecta sobre los parses de Centroamérica. Sin embargo, hay un hecho dominante que afecta a todos los pueblos de la región, hipotecando su futuro: la deuda externa, que ha alcanzado más de 400.000 .000 .000 dolares. La gravedad de la misma puede apreciarse en la tragedia que hoy experimenta el pueblo de México (deterioro de servicios públicos, aumento del hambre, viviendas deficientes, salud).

La obligación de pagar los intereses de la deuda en el contexto de una situación recesiva de la economía mundial, ha significado grandes sacrificios para las masas trabajadoras. Las exigencias del FMI han sido claras en este sentido; salarios muy bajos, cortes en los presupuestos de programas sociales, inflación seguida, en algunos casos, de deflación (Bolivia, Uruguay) y, en otras situaciones, dando lugar a medidas monetarias antipopulares (plan "Austal" en Argentina, y "Cruzado" en Brasil), que han llevado a un aumento del desempleo y de los índices de pobreza. Durante los últimos años se ha observado una disminución del número de trabajadores industriales en América Latina: por ejemplo, en Argentina, que hasta los años 70 era uno de los parses más desarrollados en el plano industrial, existe hoy un desmantelamiento de la infraestructura productiva en este sector. 
El capital financiero transnacional es el que domina actualmente la economía latinoamericana. Ha penetrado profundamente en casi todos los parses. Entró como sector de apoyo en proyectos asociados (joint-ventures), pero rápidamente consiguió consolidar sus posiciones. Estrechamente asociado al capital agrario-exportador y al capital industrial, este capital financiero transnacional es el que más se ha beneficiado durante el último quinquenio. La mayoria del pueblo trabaja para él.

Ee interesante destacar que la industria que más se ha desarrollado es la de la producción militar. Es parte considerable de las exportaciones de Brasil (sexto pars exportador de armas en el mundo) y constituye en Argentina la parte más importante de toda la producción de la industria Chile ha seguido también el mismo camino. Este desarrollo no se observa con otro tipo de producción industrial, salvo en Brasil donde la política de "reserva de mercado" eeguida por los militares para la informática ha permitido también crear condiciones para su crecimiento. Su relación con la producción bélica es innegable.

Esta situación ha resultado en una diferenciación social polarizada; una pequeña minoría posee una altrsima capacidad de consumo y de acumulación, que llega a ser insultante por su ostentación frente a la pobreza de las grandes mayorias, que sólo consiguen sobrevivir. El problema actualmente en Ámérica Latina no es el desarrollo económico, sino la sobrevivencia de las grandes masas. El desaffo de los últimos años está planteado por la necesidad de forjar un modelo económico que asegure la reproducción de la vida, la satisfacción de la necesidades básicas de todos y con la participación de todos, tanto en la producción, como en sus beneficios. Es un desafio para crear una economía de justicia y de paz para los pobres.

El capitalismo no ofrece espacio para ello. De ahí el desaffo para ejercer la imaginación y la creatividad a través de la formulación de alternativas socialistas populares; trascendiendo a la social democracia.

\section{Desafios en el ámbito de las religiones}

América Latina pasa por una situación caracterizada por una fuerte irrupción de lo religioso en el ámbito popular, que se manifiesta en la multiplicación de movimientos religiosos y de iglesias de tipo pentecostal, que expresan, a su manera, ou ruptura con la religión dominente. También se manifiesta en el proceso de renovación interna de la Iglesia católica y de las iglesias evangélicas tradicionales. Por lo que respecta a la Iglesia católica este fenómeno se expresa, con mayor o menor intensidad, mediante las comunidades eclesiales do base que surgen en los medios populares tanto en el campo como en la ciudad. Está presente en casi todos los países: tiene mayor fuerza en México, Ecuador, Bolivia; desempeña un cometido fundamental en Centroamérica y, en el Brasil, se lo considera prioridad de toda la Iglesia. Ese mismo movimiento de comunidades populares está dando sus primeros pasos en algunes iglesias evangélicas. Al mismo tiempo, en las antiguas regiones de esclavitud negra renacen los cultos afroamericanos y, también, resurgen, en muchos países, las religiones y les culturas indigenas. 
El rasgo común de todo este movimiento es su base popular, y abarca tanto las zonas nurales afectadas por los rápidos cambios sociales y económicos, como la periferia de las ciudades en la que se hacinan las masas expulsadas del campo.

Un elemento común a las comunidades pentecostales y a las comunidades de base católices es el lugar central que ocupa la lectura y el uso de la Biblia. Se constituye, asf, un nuevo sujeto histórico tanto en la lectura como en la apropiación, interpretación y difusión de la Palabra de Dios. Esta apropiación popular de la Biblia se manifiesta sea en un sentido fundamentalista que es predominante en las iglesias pentecostales, sea en un dí́logo creativo entre la vida de los pobres y la Palabra de Dios. En ambos casos, se da prioridad a la lectura, al estudio y a la celebración de la Palabra de Dios, y prevalece el espacio colectivo sobre el espacio privado e individual.

Sin embargo, subsiste una gran diferencia en cuanto al sentido de estag iglesias y comunidades. Unas surgen como alternativa religiosa para las masas desarticuladas y desemparadas de las grandes ciudades. Parece ser el caso del movimiento pentecostal, definido por un estudioso (Lalive de l'Epinay) como el "refugio de la masas." En este sentido, puede considerárselo como una forma de rechazo del mundo de la competencia capitalista exacerbada y de la marginalización impuesta a las grandes mayorías populares. Al mismo tiempo, es una estrategia de sobrevivencia tanto social, como psfquica y religiosa. Son movimientos religiosos que surgen como consecuencia del desamparo social, y que ofrecen a sus adeptos una comunidad de acogida y una ética de rechazo de los vicios de la sociedad de consumo. Favorecen la reconstrucción, en la comunidad, de un mundo fraterno, libre de la mentira, del fraude, de la explotación e imbuido de la intensa experiencia del Dios que salva. Sin embargo, el movimiento pentecostal no es para las masas populares un factor de organización ni de movilización con miras a la transformación de esta sociedad, y se adapta, de hecho, al orden existente al mismo tiempo que suscita una tensa expectativa del fin del mundo, como juicio y castigo de Dios para los malos, y justicia, alegría, consuelo y felicidad para los elegidos.

Las comunidades eclesiales de base se han desarrollado, en muchas partes, en estrecha relación con el movimiento popular, y son, a veces, la propia matriz de ese movimiento, en espcial de las asociaciones de barrio en las grandes ciudades y de los sindicatos rurales en el campo.

¿No tendrá el mismo significado el extraordinario auge de los cultos afroamericanos en los medios populares de los parses en los que hubo esclavitud negra? Tras sobrevivir en la clandestinidad, aparentemente en sincretismo con el catolicismo, $y$, hasta como parte importante del llamado catolicismo popular, expreś́ndose a través del culto a los sentos, a las tradiciones africanas, esos cultos se organizan, cada vez más, en una religión propia y autónoma. El Vudú, arrajgado en la población rural del Haitr, y el Candomblé de Bahra, de indole netamente urbana, son quizá las dos expresiones más acabadas y dinámicas de la religión afroamericana. Asimismo se expresa en la Santería cubana, en el Shago de Trinidad y Tobago y Granada, en los cultos africanos de Colombia, Venezuela, Guayanas, en el Batuque de Porto Alegre (Rro Grande del Sur, Brasil) o en el Shango de Recife (Pernambuco, Brasil). En 
el Brasil, ha surgido una nueva religión tipicamente urbana en los sectores populares negros, mestizos, de inmigrantes y blancos pobres, que reúne elementos africanos con elementos católicos orientales y, sobre todo, elementos del espiritismo kardecista: la Umbanda. En cierto sentido, la Macumba de Río de Janeiro está a medio camino entre el Candomblé tradicional de Bahra y la Umbanda con fuerte influencia blanca del sur. Además de ofrecer una respuesta al abandono social, de ser una expresión de la larga lucha por la sobrevivencia física y espiritual de la población afroemericana, los cultos africanos permiten la recuperación de la identidad étnica y de la dignidad humana de un grupo históricamente marcado por el estigma de la esclavitud y oocialmente afectado por la discriminación racial. Cultural y políticamente los centros de culto son el sustentáculo de la vida de las comunidades negras.

En el Caribe inglés y, más particularmente en Jamaica, el movimiento Rastafari ofrece una combinacion de movimiento religioso, con renacimiento cultural y mesianismo sociopolítico. Africa vuelve a ser el horizonte mútico y utópico para quienea fueron arrancados de aquellas tierras para transformarse en esclavos en Las Antillas.

Los católicos negros, que estaban organizados en cabildos en la América hispana colonial y en hermandades de Nuestra Señora del Rosario, de San Benedicto y de Santa Ifigenia, en la América portuguese, tratan actualmente de conquistar espacios propios dentro de la Iglesia, mediante la denuncia y la superación de las antiguas y nuevas discriminaciones, agr como mediante la reivindicacion del derecho a tener acceso a los ministerios y a una jerargufa negra, a una expresión litúrgica propia y a una teología que no sea ni blanca ni occidental. El criollo va ocupando el lugar del francés en la catequesio y en la liturgia católicas de Haití y de ciertos sectores de Guadalupe, las comunidades negras de Colón en Panamá revolucionan la liturgia y los cantos de la Iglesia anglicana local, mientras que las comunidades negras bautistas de Bahra comienzan a reexaminar su relación con la tradición africana.

El renacimiento indígena, siempre en profunda simbiosis con lo religioso se ha expresado en fenómenos diversos, como la recuperación de la propia tradición y dignidad en el espacio de la Iglesia catolica, como ocurrio en Riobamba en el Ecuador, o en Chiapes, México; en la constitución de una Iglesia indígena en el marco del protestantismo, como fue el caso con una Iglesia metodista entre los aimaras en Bolivia o en la recuperación de los viejos ritos, costumbres, fiestas como ocurre en Guatemala, en el al tiplano andino e incluso entre grupos que han aufrido un largo proceso de desculturación, como parte de los Bororos en el Brasil. El renacimiento religioso está en estrecha relación con la lucha política, social y sindical del mundo campesino latinoamericano. La roligión surge como un factor de resistencia, de lucha por la tierra y de recuperación de la identidad étnica y cultural.

En otro sentido, también se asiste a una fuerte agresión religioso-cultural contra el universo popular latinoamericano. Por ejemplo, es inquietante, en los medios indigenas, la actuacion del Summer Institute of Linguistic (Instituto Lingúfstico de Verano), de ciertos grupos fundamentalistas protestantes y de algunos sectores misioneros de las iglesias católicas y evangélicas, ası́ como e日 estimuladora la actitud de importantes sectores de las iglesias católica, luterana, metodista 
na, metodista, que, muchas veces, trabajan en colaboración junto a los pueblos indígenas. Vale la pena destacar en este sentido la actuación de CIM (Consejo Indigeniata Misionero) en el Brasil, del CENAMI (Centro Naciona) de Misiones Indigenas) y de iniciativas semejantes en Perú, Ecuador y Panamá.

Tambión atraviesan el mundo religioso corrientes que tienen como objetivo nuevos sectores sociales originados por la expansión de la red de servicios y del eector terciario de la economfa: las modernas clases medias que apoyan los movimientos cariomáticos tanto en las iglesias evangélicas como cat6licas. Este movimiento tiene carácter transnacional y sus fuentes organizativas e ideológicas están fuera de América Latina, tanto en Estados Unidos como en Europa. Además, continúan existiendo sectores conservadores y medios conservadoree. Ee motivo de preocupación la actuación de una organización como el Opus $D e i$, debido a su alianza con los poderosos, y al apoyo de que se beneficia por parte de importantes sectores del Vaticano y al creciente número de obispos, procedentes de la jerarquía de eae organización, que han sido designados obiepos de dícesis en el continente.

Tambión procedentes de Estados Unidos debemos señalar las asI llamadas"iglesias electrónicas," que llegan al público latinoamericano por mediación de la TV. También es importante mencionar el fenómeno de iglesias cuya expansión y consolidación se realiza mediante programas diarios de radio y no ya mediante la prensa religiosa, y que logran una mayor penetración en los sectores no alfabetizados y semial fabetizados de la población.

Particularmente en Brasil, no puede ignorarse el fenómeno de los movimientos religiosos de origen japonés. Estos movimientos se expanden entre la población de otros origenes. Se trata, sobre todo, de una religión que preconiza una paz interior, desvinculade de cualquier critica al orden social y polrtico. Este hecho es concomitante con la expansión de las transnacionales de capital nipon.

Otro desafio proviene de las complejas relaciones que mantienen las iglesias con el sector político y social en las sociedades civiles latinoamericanas y con el Estado. Los regimenes de eeguridad nacional han causado una crisis en la tradicional relación del Eetado con las diverses iglesias. En Argentina, la Iglesia colaboró con el régimen opresor y la jerarquía católica participó muy poco cuando se trató de denunciar las violaciones de los derechos humanos. Al mismo tiempo, cristianos laicos evangélicos y católicos organizaron comisiones de justicia y paz tanto en la Argentina como en el Uruguay. En otros parses estas comisiones conteron con el apoyo de la jerarquía, como es el caso de la Vicarla de Solidaridad de Chile y de El Salvador y de las comisiones de justicia y paz en el Brasil. En otros casos, como en Haitr, casi toda la Iglesia católica esumió máa directamente la resiatencia contra el régimen de Duvalier. Inversamente, es tensa la relación entre la jerarquía catolica y el gobierno de Nicaragua, aunque, al mismo tiempo, haya sido considerable la participación de los crietianos de la base en la revolución eandinista y en ou consolidación.

En Chile, bajo el régimen de Pinochet, el movimiento pentecostal ha servido de base de apoyo y de legitimación religiosa para la dictadura, lo que también ocurrí́ bajo el régimen de Rós Montt en Guatemala. 
Las relaciones entre fe y politica son una de las cuestiones cruciales para las comunidades de base en casi todo el continente y, en ciertas regiones como Centroamérica y Chile, Colombia y Perú, se enfrentan con problemes técnicoprácticos nuevos: el problema de la resistencia armada de las capas populares en eu lucha por la preservación de la vida y de la libertad de amplias meyorías, víctimas de la explotación y de la brutalidad tanto de las milicias privadas, de los "jagunços," como de la polića y del ejército; el problema del uso político de la violencia y del compromiso cristiano en favor de la paz y de la justicia. En muchos parses, como El Salvador y Chile, la Iglesia ha tenido una participacion activa en las gestiones en favor de la paz y en favor de un nuevo orden político.

Cada vez con mayor frecuencia se plantea la cuestión del trabajo conjunto entre criatianos de diferentes iglesias y con no cristianos, particulermente con manastaa, para la construcción de una nueva sociedad.

En Nicaragua la participación de gran cantidad de cristianos en el proceso revolucionario, antes y después del triunfo de julio de 1979 , la presencia de sacerdotes en el gobierno sandinista, el alejamiento progresivo de la jerarquía católica con relación al proceso nicaragüense, la tensión durante la visita del papa al pars, las medidas represivas de la jerarquía en relación a delegados de la palabra, sacerdotes y comunidades cristianas en los sectores populares, hen causado mucho sufrimiento, pero han hecho crecer el espiritu de oración, la reflexión y el discernimiento pastoral y toológico de las comunidades. Ante la agresión económica, militar, política e ideológica de la que es victima el pars por parte de Estados Unidos, Nicaragua ha planteado un grave problema a la conciencia criatiana latinoamericana en términos de solidaridad, de acciones en favor de la paz y del derecho del pueblo nicaragitense a reconstruir su pars en paz. Por su parte, Roma ha sido objeto de cuestionamientos evangélicos debido a sus posiciones, apoyos y alianzas en los conflictos de Centroamérica.

En Cuba, oe emprendió un proceso de reflexión sobre las posiciones tanto del Estado y del partido como de la Conferencia Episcopal Cubana, que culminó en febrero de 1980, con la primera asamblea pastoral del país, después de la revolución (del 1 de enero de 1959). El examen del cometido de la religión y de las iglesias en un régimen socialista en las sociedades latinoamericanas y, particularmente, en la cubana, recibí un gran impulso con el libro de Frei Betto Fidel y la religión, cuya edición cubana ouperó el medio millón de ejemplares y ha tenido un gran impacto popular.

Conviene señalar, además, el uso de la religión, estimulado por la adminiatración Reagan, en eu lucha contra la teologia de la liberación, como arma ideologica contra los movimientos populares latinaamericanos inspirados por la fe religiosa. La administración norteamericana ha impulsado el surgimiento de una casi contra-insurgencia religiosa, que cuenta con centros de investigación (Instituto de Religión y Democracia), fondos y ofensivas publicitarias y que apoya la difusión de sectas fundamentalistas con el propósito de manipular religiosamente al sector popular.

\section{Desefíos en el ámbito cultural}

Es un desaflo teológico fundamental, para América Latina, la aceptación de una reflexión basada en el diálogo con las diferentes culturas indíge- 
nas, con su propia visión del mundo y sus mitos. Nuevamente ee plantea la cuestion de si evangelizar significa destruir ese mundo. Aunque haya llegado a ser claro que evangelizar no puede ser sinónimo de europeizar o de americanizar, la teologia de la liberación no ha avanzado lo suficiente como para que sus principales interlocutores sean el mundo religioso y la cultura indigena, aef como el mundo religioso y la cultura afroamericana que constituyen la masa de los más pobres y explotados.

El desafío inverso es el del diálogo crítico entre fe y teología con la cultura dominante de los sectores técnicos, cientificos y culturales relacionados con la universidad, la investigación, la producción industrial, la expansión de la informatización de la sociedad con su nuevo lenguaje y sus nuevos presupuestos. Cuestiones nuevas relativas a la ingenierla genótica, la investigación con seres humanos, la ecología y el amamento nuclear aún no han tenido repercusión y reflexión suficientea en las comunidades cristianas y en los sectores teologicos de la liberación, que aún no cuentan con los instrumentos necesarios para responder a esa nueva problemática.

Un sector teológico más vinculado a una teologia académica y a la tradición de una Iglesia comprometida con las clases medias a través de ou red de colegios y universidades, insiste en que el desafio central que se plantea a la teología consiste precisamente en la emergencia de una sociedad y de una cultura urbano-industrial, técnico-cientifica. En otras palabras, el desafio principal está planteado por la modernidad, entendida como emancipación de la razón, del progreso científico, de la expansión industrial y tecnologica dirigida por la burguesía no ya nacional sino internacional, casi siempre aliada a la tecnoburocracia de los estados nacionales latinoamericanos. Según este sector, la única esperanza para poder superar la miseria y el empobrecimiento depende del progreso de estos sectores tanto en el campo como en las ciudedes, favoreciendo, mediante la modernización de la economía, el aumento de la productividad agrícola e industrial y una mayor oferta de productos esenciales, y corrigiendo los abusos y desvíos actuales mediante la acción del Eatado y la aplicación de la doctrina social de la Iglesia.

Para este sector teológico, la solución térica a los problemas actuales ea decir no a la teología de la liberación y si a la doctrina social de la Iglesia, es decir no a las clases populareo y si a las clases medias educadas, consideradas el sujeto historico de los cambios.

No se puede negar la existencia de las cuestiones planteadas por la modernidad, pero ésta adquiere una connotación diferente en América Latina y au lectura no es la misma que la de la versión clásica.

Según esta versión, como consecuencia de la revolución industrial, surgió una clase dirigente, la burguesfa con su ideologia o liberalismo, pero también surgió, simultáneamente, una clase explotada, el proletariado, con au visión critica del proceso, gracias al socialismo y al marcismo.

Responder a la modernidad no significa responder únicamente a las cuestiones planteadas por el liberalismo y la burguesra, sino también, y con igual rigor, a las cuestiones planteadas por la clase obrera y por el marxismo.

En América Latina, la modernidad capitalista necesita una lectura diferente por lo menos en tres aspectos. 
Históricamente, la modernidad no condujo al eurgimiento de una clase dirigente y de una nación libre e independiente, como en el proceso europeo, sino a la sustitución de la dominación ibérica por la dominación británica y después la norteamericana. El eurgimiento de las burguesías nacionales fue un proceso ilusorio, incluso en paŕses como México, Argentina, Brasil, con una industrialización más antigua y mercados más amplios.

Econbmicamente, la industrialización europea condujo a una "modernizacion" principalmente y, en primer lugar en el campo. La clase protagonista del proceso, a finales del eiglo XXX y comienzos del siglo XX, fue el hacendado del cafó en el Brasil, en Colombia y en diversos parseo de Centroemórica, el gran hacendado productor de trigo, de carne y de la lana en la Argentina y en el Uruguay y la clase explotada fue el colono o el agalariado agrícola, asi como los pueblos indígenas expropiados de su tierra y subordinados a la agricultura comercial de exportación.

Socialmente, el proceso llevó a la marginación de las grandes masas que no se integraron a eso sectores "modernos" de la economía ni en el campo ni en la ciudad.

Asr pues, la modernidad en América Latina plantea la cuestion de la dominación y de la explotación capitalista como un problema nacional, como un problema de la clase obrera, como un problema del campesinado, asi como, y sobre todo de los pueblos indígenas y de las grandes masas marginadas en el campo y en la ciudad.

La teología de la liberación, crítica del capitalismo en esa dimensión imperialista, a través de la teorfa de la dependencia, sensible al abandono y al sufrimiento de las grandes masas, a través de la opción por los pobres, cada vez más comprometida con el mundo indígena, a través de organiemos pastorales o con las luchas en el campo, a través de una teología de la tierra, no se ha eproximado suficientemente a la clase obrera para poder responder a eus interrogantes en lo social, lo político y lo religioso. Aún no ha respondido debidamente a la cuestión de las aplicaciones précticas del mundo tecnológico y cientrfico en loe parses del tercer mundo, lo que plantea cuestiones éticas y teológices diferentes a las que se están examinando en el primer mundo.

El desafío actual de la teología de la liberación es procurar responder a esos interrogantes que plantean las culturas especfficas y a los interrogantes propios del mundo indrgena, del mundo afroamericano, del mundo de la técnica y de la ciencia, del mundo obrero, del mundo de la mujer pobre y marginada y del movimiento feminista en general.

En el campo cultural, la oligopolización plantea otro desafío o el monopalio de los medios de comunicación social, eobre todo de la televisión. Son comunes las prácticas de manipulación, la distorsión de la información e incluso las campañas directas contra los intereses populares y loe sectores de las iglesias comprometidas con los más pobres. Las empresas de comunicación están casi todas supeditadas a los intereses empresariales, y son la parte visible del iceberg que representan las máquinas publicitarias de las empresas, en particular de las multinacionales que subvencionen junto con el Estado los mayores gastos en publicidad.

Todos nuestros parses se ven efectados por el control internacional de la circulación de noticias periodrsticas e invadidos por la industria cultural de los 
parses de capitalismo avanzado. Los medios de comunicación social se vuelven instrumentos fundamentales del proceso de dominación cultural e ideológica de Estados Unidos.

Por otra parte, se asiste a un proceso de resistencia popular y de gran creatividad en el sector de la producción cultural, destacándose la canción latinoamericana.

Esta creatividad se manifiesta también en la Iglesia de los pobres que cuenta actualmente con su himnario propio, su producción biblica, sus cartillas políticas y sociales y sus artistas plásticos y dibujantes, además de sus cantores, músicos y poetas.

Este reencuentro de la religión popular con el arte es uno de los aspectos más promisorios de la nueva manera de ser Iglesia, en su expresión cultural.

Del mismo modo avanza la recuperación de la memoria histórica de los pobres y de los oprimidos de sus tradiciones, de su resistencia y de sus luchas, como sustento y gura para las luchas actuales, como fuerza y esperanza ante los sufrimientos y las adversidades. En este contexto, es válida una reflexión más comprometida en torno al tema de las expresiones rel:giosas del pueblo, superando la falsa identificación entre religión popular y enajenación, entre herencia indígena o negra y superstición, que había inducido a que sectores de la teología de la liberación, en sus inicios, librasen un combate intransigente contra la llamada "religiosidad popular."

\section{Las metodologias utilizadas en las prácticas teológicas del continente americano}

\section{a) Teología en el tercer mundo y a partir del tercer mundo}

Hay tantas teologias cuanto prácticas organizadas de las iglesias. Continúan existiendo las prácticas de iglesias que prolongan el pacto colonial y neocolonial, pues se articulan con las capas dominantes de la sociedad. La teología que acompaña la vida pastoral de este tipo de Iglesia es generalmente conservadora. Su orientación es neoescolástica. Hay prácticas de iglesias modernas, cuya base social constituyen sectores progresistas, abjertos al proyecto de reforma social. En este caso, la teologia también es moderna, de conformidad con los centros metropolitanos de pensamiento cristiano, de estilo crítico y académico. Pero también hay iglesias que, ante la miseria de las grandes mayorłas, han tomado en serio la opción preferencial por los pobres. Cuentan con una práctica popular, consideran al oprimido como el principal sujeto de la liberación y se asocian a él en su práctica pastoral. La teologia que acompaña e ilumina esta práctica es una teologia de liberación.

En América Latina coexisten, no sin tensiones, estas y otras corrientes teológicas. Por el hecho de que nuestro continente es un continente dependiente y asociado al capitalismo central, la teologla participa también, a nuestro entender, de esa dependencia y asociación. Pero, por el hecho también de la existencia de procesos de liberación a partir de los oprimidos, hay, asimismo, una teologra adecuada a esos procesos a la que se ha denominado teologia de la liberacion. Queremos detenemos en esta corriente de la teologia porque la considera- 
mos la más representativa de América Latina. Demuestra no sólo que hay teólo. gos en el tercer mundo latinoamericano, sino también, y sobre todo, que hay teólogos del tercer mundo que piensan la fe del pueblo a partir de la situación de opresión del tercer mundo, con miras a una liberación integral.

\section{b) Reflexiones relativas al punto de partida}

La teologia de la liberación en América Latina ha penetrado prácticamente en todo el ámbito eclesial. Hay una teologfa de la liberación popular hecha por los participantes de las CEBs y de los ćrculos brblicos. Formula comentarios, realiza celebraciones, dramatizaciones e indica caminos para la acción, y da un lugar preponderante al lenguaje popular e informal. Existe, además, una teologla de la liberación pastoral, hecha normalmente por pastores y agentes de pastoral. Se elabora principalmente en las asambleas eclesiales y encuentros de profundización y de planificación pastoral. Utiliza la lógica de la acción que es concreta dinámica y profética. Por último, está en una fase avanzada de elaboración una teologia de la liberación profesional, hecha por teólogos profesionales, de indole metódica y cientifica, cuya producción se utiliza en cursos, asesoramientos y escritos.

Para todas estae formas de teologia de la liberación existe un presupuesto fundamental: el compromiso real con los oprimidos. para que haya teologia de la liberación es requisito previo que haya un compromiso con la liberación concreta de los empobrecidos. El punto de partida no es simplemente la realidad de explotación de la que son víctimas los oprimidos, sino las prácticas de los cristianos y de los pobres en general que actúan para que esa situación de opresión se transforme. El te6logo participa de ese proceso. Es a partir y por razón del mismo que elabora su teología. El oprimido no es únicamente un punto de referencia de la reflexíón libertadora ni simplemente su destinatario. Es, ante todo, el sujeto y el actor de la liberación. Sus reflexiones se incorporan en la reflexión del té́logo de tal forma que la teologia termina siendo una producción comunitaria. No es solamente objeto de la interpretación teológica, eino, principalmente, intérprete de su propia si tuación a la luz de la fe.

Esta práctica procura ser eficaz. Por ello, es necesario un análigis más critico de los mecanismos que causan la opresión y de las estrategias de liberación a la luz de la fe cristiana. En los últimos cinco años se ha profundizado la mediación socioanalítica. Las explicaciones empiristas y funcionalistas del empobrecimiento (la pobreza como vicio, en el primer caso y como atraso técnico en el segundo) fueron ampliamente superadas. Por otra parte, la interpretación dialéctica (la pobreza como opresión) de la tradición manasta, ampliamente aceptada por las principales tendencias de la teologia de la liberación, ha sido objeto de algunos enriquecimientos que conviene destacar.

En primer lugar, se ha ampliado el concepto de pobre. Es, por supuesto, el pobre socioeconomico real, pero tiene rostros concretos y sufre opresiones especfficas sea que se trate del negro (opresión de tipo racial), del indio (opresión de tipo étnicocultural), de la mujer (opresión de tipo sexual). Es preciso percibir estas opresiones en sus diferencias teóricas y prácticas. En este sentido, a partir de la lectura cristológica del empobrecido, hay una recuperación de la figura del "lumpen," que el análisis marxista coloca, en cierto sentido, al margen. Los 
que lo integran son los más pobres entre los pobres (como los hansenianos, los boia-frias, la mujer marginada y prostituida, el menor abandonado o explotado, los impedidos fivicos y mentales, los habitantes de les favelas, los posseiros, etc). Todos ellos deben participar en el proceso de liberación a partir de sus opresiones especificas. Son los propios pobres quienes dan una interpretación de su miseria que no deja de lado el análisis critico sino que lo enriquece. Asr, los pobres se consideran a si mismos como hijos de Dios, hechos a ou imagen y semejanza, pero destigurados por los opresores, humillados y ofendidos. Esta referencia concreta se incluye en las consideraciones más formales de fndole socioanalitica.

En segundo lugar, se ha valorizado más la resistencia de los pobres ante la opresión y eu lucha por una liberación mayor. El oprimido no se puede comprender únicamente a partir del opresor, sino también por la manera como reacciona contra la opresión. Durante los últimos años, en particular gracias a la contribución de la CEHILA, se ha tratado de recuperar la memoria de las luchas de los pobres, de sus martirios, de sug avances. Ellos son también sujetos sociales - aunque se encuentren bajo un régimen de aometimiento-y sus sueños de libertad y de una sociedad distinta continúan alimentando la resistencia y el compromiso en favor de la transformación social.

En tercer lugar, en eate proceso de liberación, se ha prestado una atención especial al aspecto pedagógico. Se trata de comenzar de abajo, de las prácticas populares, de la valoración del saber vital del pueblo, de sus formas comunitarias de actuar, de los valores de su religiosidad. En ese proceso se procura vivir una democracia real. Los liderazgos se constituyen manteniendo el contacto con las comunidades.

Los elementos del análisis marxista de lo social no se utilizan nunca como instrumentos ya acabados de conocimiento. Se utilizan a partir del proceso liberador de los pobres que luchan contra la explotación y en función de ellos se enriquecen mediante una actitud de libertad critica.

\section{c) La importancia de la Biblia en Ia hermenéutica de la liberación}

Del ver analf́tico y concreto se pasa al juzgar a la luz del mensaje cristiano. Durante los últimos años ha habido una apropiación creciente de las Escrituras por parte del pueblo. La Biblia constituye el gran código de lectura de las opresiones sufridas y, también, una fuente inspiradora para la liberación y la vida.

En primer lugar, se lee la Biblia a partir de las prácticas de los pobres que se organizan en sus comunidades y grupos de acción reflexión. No ee trata de leer las Escrituras a partir de los pasajes o versículos que hablan más directamente de la opresión liberación. Se trata de leer toda la Biblia desde la perspectiva de los pobres que descubren en ella la historia de un pueblo oprimido que, a la luz de la fe, buscó resistir todas las opresiones y cautiverios y luchó por su vida libre y liberada. Por supuesto, el exodo, los profetas, Jesús y el Apocalipsis tienen un lugar privilegiado, pero no son exclusivos.

En segundo lugar, una lectura liberadora de la Biblia examina con atención las condiciones materiales y sociales en las que se escribio el texto. Asi, se verifica una coincidencia entre los pobres 
se verifica una coincidencia entre los pobres de la Biblia y las condiciones impuestas por la opresión, y los pobres de hoy y su situación inhumana.

En tercer lugar, se trata de valorizar la fuerza de compromiso y de transformación que está presente en toda la Biblia. Importa llegar a la conversión personal y a la liberación social. Esto no significa utilizar las Escrituras, sino respetar su naturaleza y entrar en su dinamismo que está abierto al mesianismo y al reino que viene del futuro en dirección al presente. Asi pues, se trata de una interpretación que no se contenta con una explicación del texto, sino con su aplicación. La Biblia es un libro de vida y no de historias interesantes.

Por úl timo, la lectura biblica es comunitaria. Se lleva a cabo en el marco de ese proceso de liberación, en los momentos de reunión de la comunidad, en un contexto de reflexión sobre la vida y de celebración. Esa eclesialidad constituye el ambiente hermenéutico y favorece la unión en la lucha más que la diver. gencia de opiniones.

La importancia de la Biblia en la lucha por la liberación adquirió tal significado que surgió la necesidad de dar al pueblo y a las agentes de pastoral textos de apoyo más sistemáticos y completos. Así pues, ya se comenź a publicar en el Brasil, con la colaboración de algunos biblistas hispanoamericanos un "Comentario popular de la Biblia," que incluye todos los libros brblicos. Se observa con satisfacción el creciente interé de los agentes populares por aprender las lenguas biblicas (griego y hebreo) para poder conocer mejor el mensaje liberador de Dios.

\section{d) La tarea constructiva de la teología de la liberación}

Además de la profundización del estudio brblico, ha habido durante los últimos cinco años un avance significativo en cuanto a la sistematización de la teologla de la liberacion. Asimismo se han afirmado algunas orientaciones significativas en el marco de la tendencia común: a partir del oprimido en favor de su liberación.

En primer lugar, ha habido una recuperación más amplia del contenido de la gran tradición teológica. No sólo se han consolidado la cristología y la eclesiologfa, sino, principalmente, el tema del Dios de la vida y de la comunión trinitaria (la Santŕsima Trinidad es la mejor comunidad), la espiritualidad de compromiso, de lucha y de martirio, la antropologla del hombre y de la mujer nuevos, y la importancia del Espíritu en las comunidades.

La historia latinoamericana, contada a partir de las victimas (los indios, los negros y los otros oprimidos) ha ayudado a definir más concretamente la evangelización, a descubrir la memoria del pueblo oprimido, a valorar sus luchas históricas y a reubicar la pastoral con respecto a las otras clases sociales, que son evangelizadas a partir de la opción preferencial por los empobrecidos.

Se ha abierto un campo fructifero al estudiar más sisteméticamente la relación entre teologfa y economfa. Ha permitido desenmascarar más fácilmente los fdolos del sistema capitalista, y contra ellos y a favor de los pobres, realzar al verdadero Dios que es vivo y dador de vida. A partir del Dios vivo se descubre la fundamentación teológica de la opción por los pobres: nace de la propia naturaleza de Dios. Por ser vivo y dador de vida, Dios mismo opta por los pobres amenazados en su vida y condenados a "morir antes de tiempo." 
Hombres y mujeres se han mostrado más dispuestos a comprender la dimensión femenina de la realidad persona] y social. Algunas mujeres han comenzado a hacer teología a partir de su condición de mujeres, históricas y socialmente sometidas al partriarcalismo y al machismo tradicional. A partir de esta situación, emergieron temas nuevos propios de la especificidad femenina.

Por último, la teologia de la liberación es cada vez más ecuménica. Lo es tanto por sus origenes como en sus prácticas y en sus objetivos. La opresión y la liberación no son confesionales. La opresión afecta a todos de manera diferente y la liberación se destina a todos comenzando por los oprimidos. Muches confesiones cristianas, en el marco de la teologia de la liberación, entran en profunda comunión para poder sumar sus fuerzas en el cumplimento de una misión común: el servicio de la liberación.

\section{Contenido y orientaciones}

\section{Cuestiones}

Los pobres son el asunto central de la teologla'de la liberación. En eso no radica la novedad de la misma. Esta temática está en su propio núcleo original. En ella los empobrecidos fueron afirmados como agentes teologicos y pastorales privilegiados. Lo importante es que la novedad reside sobre todo en la profundización de la opción por los oprimidos. Los pobres son empobrecidos, su condición es consecuencia de la injusticia social. Por eso, su condición tiene que ser percibida necesariamente a través del prisma del análisis sociológico y económico. No obstante, es preciso no generalizar la situación en la que se encuentran. Los pobres tienen muchos rostros. Es urgente percibir que su rostro es de mujer, de indio, de negro, de menor carente y abandonado.

El itinerario seguido por las comunidades puso en evidencia la opresión a que es sometida la mujer. En una sociedad dominada por el hombre, sus derechos son coartados, su condición menospreciada, sus salarios son más bajos. Las negras y las indias sufren opresiones múltiples. La pastoral de la mujer pobre exige nuevos enfoques, entre los cuales que la teología sepa tomar en cuenta el cuerpo. Una teologia hecha por las mujeres y desde la perspectiva de la mujer pobre, comienza a tomar forma en América Latina.

El pobre tiene rostro de indio, de negro, de mestizo o de mulato. Tiene marcas especiales. La voz que negros e indios se arrogan el derecho de expresar pone el acento en esa diferencia. Sus religiones y culturas ofrecen contribuciones propias a la liberación de nuestros pueblos. A estos rostros se suman otros. Cada uno con su peculiaridad. A medida que hemos ido percibiendo con mayor profundidad estas diferencias, nos damos cuenta del radicalismo de la teologfa que parte desde los pobres. El rostro del Dios de la vida se ha hecho más diáfano y preciso.

Dios crea la vida. Esta experiencia de fe en Dios que, en su gratitud, genera vida en abundancia, atraviese la tradición eclesial. Es una tradición antigua y universal al mismo tiempo. Torna a ser viva en medio de los pobres. Las matanzas los exterminan y la explotación socio-económica los degrada en su condición de seree humanos. A pesar de esta situación, pueden proclamar: "iEl vive!" Una mística pascual permea los gritos y gemidos de los oprimidos. Cada 
martirio es como si fuese el último, aquel que pone fin a la injusticia. Con una voz megiánica, pueblos enteros proclaman al Dios de la vida

El Dios de la vida es el Dios Padre. Pero también en este sentido hay un progreso significativo. Al fin de cuentas, la categoria de "Dios padre" todavia es muy provisoria; no está del todo exenta de influencias androcéntricas. Hablar de Dios como del Dios de la vida es un peso hacia adelante, pues se califica la experiencia de Dios.

El Dios que promueve la vida es celebrado con vida. Durante los últimos cinco años se consolidó la dimensión litúrgica de las comunidades. Estas oran y celebran con intensidad. Se dedican a cantar sue dolores, ous progresos y sus utopias, pues los pobres valorizan su poesfa y sus gestos. Evangelizan a través de la liturgia y aó, se apropian de la teologia. Dan más impulso a la fuerza de los pobres con su fe en el Dios de la vida.

Los acontecimientos litúrgicos son experiencias de gran importancia para los agentes de pastoral y los teólogos. Nos convierten a la oración. Nos hacen cada vez más escépticos de la omnipotencia del discurso racional, a la vez que nos alientan para correr el riesgo de lo místico y lo simbolico. El Dios de la vida celebrado en las liturgias del pueblo influye fuertemente nuestra teología.

Esta experiencia del Dios de la vida no se limita a las celebraciones litúrgicas. Ella impulsa al testimonio en medio de los procesos historicos. La militancia en el movimiento popular y en las organizaciones políticas del mismo es una consecuencia casi inevitable. La participación de los crietianos en la vida politica, por un lado, muchas veces significa alejarse de las comunidades cristianas y, por otro lado, también puede crear divisiones y contradicciones internas en las mismas. De ahf que en el correr de los últimos meses haya surgido la neceaidad de desarrollar una reflexión teológica para acompañar la militancia política de los miembros de las comunidades cristianas. El contenido de esta reflexión constituye una propuesta para una ética política liberadora.

La lucha no se da sólo en el campo político, fuera de las iglesias. Como se ha señalado en la Introducción, también hemos tenido que defendernos. La contestación a la teologia de la liberación caracteriza su trayectoria desde el comienzo. Ha habido ataques contra ella tanto por parte del protestantismo como del catolicismo. Sin embargo, esos ataques ganaron especial intensidad durante loe úl timos tres años. Los objetivos de esas embestidas fueron principalmente Gustavo Gutiérrez y Leonardo Boff. La pena impuesta a este último fue la culminación de este proceso. En esas circunstancias se impuso la defensa y la justificación de las razones de fe de la teología de la liberación.

En el marco de egtas circunstancias se puso en evidencia cuán ligada está la teología de liberación a la Iglesia. No se trata de una elaboración de librepensadores, sino de télogos y agentes de pastoral integrados a la vida eclesial.

Del miemo modo, el debate en torno a la teologia de la liberación ha mostrado cuán profundamente enraizados en el pueblo están los teólogos que comparten esta manera de hacer teologia. Las comunidades se moviliizaron con gran dinamismo. Oraron y celebraron. La teologia de la liberación paso a ser un asunto discutido en las calles y a ocupar los titulares de los periódicos. La teologia de la liberación llegó al gran público. Ante impugnaciones y críticas 
se han formulado nuevas perspectivas teológicas. Después de la publicación de las dos instrucciones, están planteados nuevos desaffos.

Finalmente, el debate ha ayudado a aclarar también de qué manera estamos insistiendo en un nuevo enfoque, en un nuevo método de hacer teologia. La teologia de la liberación no está ni completa ni terminada. Es un nuevo punto de vista: a partir de la práctica liberadora de los pobres.

Esta referencia fundamental a la práctica liberadora de los pobres exige tomar muy en cuenta no solo las luchas populares, sino también las expresiones religioses del pueblo pobre. Eate asunto no es novedad para el catolicismo, pero constituye una exigencia nueva para el protestantismo. Los teologos protestantes entienden hoy que es una exagencia prioritaria acoger en au reflexión teológica las formas religiosas a través de las que se expresa el pueblo pobre.

Tanto el catolicismo como el protestantismo están convocados por los pobres de América Latina a comprender que la modernidad no se limita a la erudición académica de los grupos dominantes. Es urgente percibir el carácter dialéctico de esa modernidad: junto a la ilustración académice, muchas veces en tensión con ella, se desarrolla el saber de los trabajadores, que se expresa a través de formas populares, lo que significa la pérdida de esa modernidad. Esto no fue percibido por quienes, en la conferencia del episcopado católico en Puebla, hicieron la propuesta de una "teologia de la cultura," según la cual el gran desafio para la evangelización de Latinoamérica era la cultura urbana, donde se enfatiza la ciencia y la téenica. Esa es la modernidad del opresor. Junto a ella ha ido tomando forma una cultura del oprimido. En este euelo crecen los gérmenes de la liberación. De ahr la neceaidad de referirae a las tradiciones y valores populares, que tienen un instrumento privilegiado de expresión en las religiones de los pobres.

Este camino teológico liberador es ecuménico. Nació ecuménico. Una teología de la liberación que no fuese ecuménica, hasta serfa un contrasentido. $\mathrm{Ni}$ siquiera es posible formularla de manera exclusiva. Su inclusividad es una marca de origen. Esta merca ecuménica, empero, no siempre es visible. Los protestantes son pocos en Latinoamérica. Son minoria. En estas circunstancias, lo normal sería que predominasen los catolicos. No obstante, de hecho, prevalece la solidaridad ecuménica. Se trabaja en una relación de hombro a hombro, codo con codo.

En el ecumenismo ejercitamos la converaión. En la abertura de unos a otros, el encuentro con el otro. Protestantes y catolicos se convierten a los que les es diferente. Cada cual es descubierto en su diferencia. Hay, asi, un enriquecimiento mutuo y progresos ecuménicos.

Sin embargo, el ecumenismo no se limita a las relaciones entre católicos y protestantes. No se agota en una relación interconfesional. La trasciende. Es elemental la conversión al pobre. En esta relación entre distintas tradiciones confesionales y la resistencia del pueblo pobre tiene lugar la interacción ecuménica más creativa. En este campo especffico surgen las sorpresas mayores. Por un lado, el pueblo se aproxima. Diferentes comunidades confesionales descubren que están caminando en el mismo sentido. Por otro lado, cuando volvemos a considerar las diferencias confesionales a la luz de la práctica popular, 
descubrimos cuán próximas están les confesiones unas de otras. Los pobres enseñan a percibir semejanzas a través de las diferencias confesionales. El rostro de los pobres se transforma en imperativo ecuménico.

Se ha criticado a la teologia de la liberación por no ser universal, sino limitada a un determinado horizonte geográfico. Sin embargo, la conciencia de la teologia de la liberación tiene una dimensión universal, mientras se formule a partir de la perspectiva del empobrecido y oprimido es universal, pues la pobreza y la opresión son fenómenos mundiales. Es todo lo contrario de la teologia que se elabora generalmente (hay excepciones, sin embargo) en los centros dominantes, y que tiene una perspectiva propia del poder y del imperio. En ese sentido, la teologla occidental establece límites a las teologías del tercer mundo, olvidando que ella misma es limitada. Pretende ser univereal, y por eso mismo es dominadora. El carácter mundial de la teología no depende de una perepectiva geográfica, sino de sus opciones sociales y culturales.

Por último, desde el CELAM se ha lanzado la propuesta de formular una "teologia de la reconciliación" en el contexto latinoamericano. Ante las luchas sociales que sacuden la realidad latinoemericana, se entiende como elgo necesario subrayar la conciliación de clases antes que los conflictos entre las mismas. En este caso generalmente se abandona la perspectiva del pobre y del oprimido. Generalmente, los adeptos de la reconciliación eccial la entienden de arriba hacia abajo. Entonces, para los pobres, reconciliación eignifica resignación. La reconciliación operada por Jesucriato es un proceso que pasa por la cruz. Los pobres ya tienen la suya; son "los cristos azotados de las Indias." O, como se dijo en Chile cuando dos jovenes fueron quemados vivos por las fuerzas opresoras: "Jesús quemado entre los jóvenes." Los ricos también deben aceptar la cruz. O sea, el rico debe aceptar la necesidad de cambio, de arrepentimiento: dejar de ser dominante y compartir lo que ha acumulado con injusticia. Esta necesidad de justicia domina en la reconciliación desde la cruz. De no ser asi, "reconciliación" significa opresión y mantenimiento del statu-quo.

\section{Elementos comunes y diferencias}

Para América Latina el conocimiento y el diálogo con las realidades y las teologias je los otros continentes, en particular a traves de EATWOT, ha sido enriquecedor y muy decisivo. Los teologos de América Latina han abierto sus ojos a otras realidades, han relativizado su propia experiencia al verla situada en un contexto más global y se han sentido desafiados a hablar de Dios a partir de otras culturas.

Al mismo tiempo, es necesario reconocer que el dí́logo es un aprendizaje lento y difícil. Se necesita tiempo para percibir la verdad del otro y dejarse interpelar por esa verdad que puede cuestionar las propias certezas. EATWOT será realmente un lugar privilegiado de enriquecimiento cuando ae coneolide un proceso de confianza mutua.

\section{Elementos comunes}

A la luz de los encuentros realizados por EATWOT y del conocimiento formal a través de lecturas, viajes y otros contactos, se pueden señalar algunos de los elementos comunes. 
Las teologias del tercer mundo son teologfas periféricas en relación a los centros tradicionales del poder, del saber y del monopolio cultural del evangelio de Jeeucrieto.

Desde el punto de vista historico y social han nacido y se siguen desarrollando en los amplios eepacios geográficos y humanos de los pueblos colonizados y explotados durante eiglos. Al adquirir la independencia poĺtica e iniciar un proceso autónomo de desarrollo, los cristianos de esos continentes y regiones han afirmado el derecho a pensar au fe en la matriz vital de sus propias tradiciones culturales y religiosas.

Estas teologias crecen en el contexto de una ruptura con los modelos históricos y culturales de la experiencia particular de la civilización occidental. Si bien es cierto, que les burgueslas y eectores dominantes, sociales y eclesíasticos, de los parses del tercer mundo participan en el proyecto global de los parses centrales, las grandes mayorias de los pueblos oprimidos expresan su experiencia religiose de otras fuentes de inspiración y sabiduría.

Se ha producido una ruptura entre eatas teologías y el modelo clásico de las iglegias centrales, catolicas y proteatante, que consideraban y que todavia consideran que hay un sola teologia, porque "hay un solo Señor y un solo bautismo." En el tercer mundo se ha llegado a considerar esta interpretación como una manera de imponer un dominio mieionero y teológico. Los distintos contextos y espacios culturales y religiosos no son espacios vacios ni "tierra de nadie." El Eepiritu de Dios ha estado activo derramando sus dones de sabidurfa y de vide mucho antes de que llegaran las minorfas occidentales. Las teologias contextuales son expresión de la riqueza de la humanidad y de la vocación de celebrar la presencia de Dios en todos los pueblos y en todas las culturas.

El conocimiento mutuo ha revelado que hay elementos comunes en la metodología de estas teologiae. Eatán influenciadas por la experiencia dolorosa y humillante de "los condenedos de la tierra." Se expresan y ge formulan como grito de rebeldía y de protesta contra la dominación de la raza blanca occidentel y contra los modelos de desarrollo. Al mismo tiempo, son la expresión de una nueva manera de hacer teologia a partir de esas experiencias dolorosas. Es un fruto promisorio de las iglesias jovenes del tercer mundo.

Por esta razón, son teologlas que no se limitan a repetir lo pasado ni a copiar lo que otros han dicho antes. Sin renunciar a las riquezas de una tradición que tranemite lo original y auténtico de la experiencia de Jesús de Nazaret, pretenden releer ege acontecimiento a la luz de sus propios libros sagrados y experiencias religiosas.

El sujeto actor y punto de referencia es el pueblo pobre. El pueblo que busca su identidad historice y que lucha contra todas las formas de explotación y dominación cultural, religiose, política, económica y social.

Son teologias précticas y pastorales, relacionadas con la vida y la muerte de las personas. No es una teologia académica, elaborada en los ámbitos cerrados de las instituciones eclesiáaticas. Eatá hecha en primer lugar, por las comunidades cristianas, inepiradas por sus experiencias historicas y culturales y enfrentadas con las fuerzas de opresión y con los ídolos de la muerte, que pretenden reemplazar al Dios vivo. 
La experiencia de ruptura con el pretendido modelo único de la teologia central, permite desarrollar otro sentido de la universalidad. El mundo actual oe ha hecho diverso, rico y plural gracias al acercamiento que han facilitado las comunicaciones. Hoy dí, el mundo tiene mayor unidad y al mismo tiempo se reconocen mejor las riquezas particulares y la diversidad.

La universalidad de la teología corresponde a la riqueza de la oikoumene Por primera vez, el mundo está més cerca de ese ideal, al mismo tiempo que nuevas fuerzes de disgregación lo amenazan.

Las teologias del tercer mundo no pueden aceptar la unidad y la univerealidad a partir de los centros geográficos y culturales que representan la vieja experiencia de una civilización cansada que decae progresivamente. La nueva universalidad será el resultado de una relación ecuménica donde todas las religiones y humanismos expresarán el anhelo infinito de las personas.

En este mismo sentido, las teologias del tercer mundo desde el comienzo se han presentado como "ecuménicas." Ecuménicas en un sentido amplio y global. No solamente rechazan las viejas rivalidades denominacionales que les im. pusieron los misioneros occidentales, aliados con las fuerzas colonizadoras y genocidag, sino que además so abren a todas las expresiones religiosas de sus propias tradiciones, participan de diversas formas de encarnación e inculturación de lo más válido del mensaje de Jesucristo, redescubren la verdad de sus propias tradiciones y entran en diálogo para llegar a nuevas formas de sintesis y sincretismo.

Respecto a las orientaciones y contenido, los elementos comunes de estas teologías provienen de las semejanzas de su punto de partida y de su metodologia. pero, esto mismo marca sus diferencias. Precisamente porque se trata de teologias contextuales, que parten de la experiencia religiosa y pastoral de los cristianos en dí́logo con no-cristianos, ha habido un caminar en estos años pasados que permite delinear sue características comunes.

Ea diffcil señalar a priori como se habla y se celebra a Dios en cada cultura, qué aspectos de la persona de Jesucristo expresan mejor las aspiraciones de los diferentes pueblos y qué frutos del Esṕritu son valorados por las comunidades eclesieles de cada continente.

Los puntos 2 y 3 de este informe señalan la experiencia latinoamericana de los últimos años. Será més apropiado recoger estos elementos comunes al término de la asamblea general de Méxcico, tras haber escuchado la experiencia de todos los contienntes.

\section{Diferencias}

Las diferencias legitimas de las teologfas del tercer mundo vienen de sus particulares experiencias culturales y religiosas. Estas deben ser respetadas y valoradas. El conocimiento de esas riquezas propias ha sido uno de los frutos más positivos del diálogo de EATWOT.

Pero hay otras diferencias que provienen de las imposiciones de los antiguos migioneros o actuales grupos eclesiásticos dominantes. Persisten en el tercer mundo teologias "conservadoras" o incluso "progreistas," que conviven sin problemas con las fuerzasde opresión y que no interpretan las aspiraciones legítimas de los pueblos. 
También hay que reconocer que entre los mismos representantes de] tercer mundo hay formas larvades de desconocimiento, desconfianza, falta de respeto o pretensiones de universalidad que han darado la convivencia, pero que felizmente parecen haber sido superadas en EATWOT.

Desde la perspectiva latinoamericana se perciben diferencias en el grado de ruptura con occidente. Mientras América Latina está más inserta en los patrones culturales y sociales de la tradición europea, Africa y Asia mantienen mejor ou identidad que se alimenta en sus propias raíces culturales e historicas.

Esta diferencia ha ayudado mucho a los teólogos de América Latina al alertarlos acerca de los grupos indígenes y negros del continente.

Otra diferencia proviene del peso cualitativo de los cristianos en cada región. Mientras en Asia la presencia de los cristianos es minoritaria, crece rápidamente en Africa y constituye un elemento masivo y sociológico en América Latina.

Los télogos de América Latina admiran la riqueza de las tradiciones orales de Africa, los cantos de la religiosidad negra de Estados Unidos y admiran la importancia de los libros gagrados de las religiones de Asia.

Uno de los puntos que llama la atención es el énfasis diferente en el uso de mediaciones para la reflexión teológica. En América Latina, sobre todo en la primera etapa, se ha priviligado la importancia de las mediaciones socioanalíticas. Estas han ayudado a descubrir las causas que impiden la realización concreta del amor al prójimo, según la parábola del Buen Samaritano.

Los latinoamericanos se han sentido enriquecidos por la ayuda de los otros continentes para introducir en su análisis los conceptos teóricos de raza, cultura y discriminación sexual, que les han facilitado un mejor conocimiento de la persona oprimida.

Entre los té́logos de América Latina se aprecia mucho la teología de Corea y de Sri Lanka. Valoran los esfuerzos de una teología africana y miran desde lejos con interés la riqueza y sabiduría de las grandes religiones de Asia y Africa .

A través de estas semejanzas ae afirma la vocación común de los cristianos y télogos del tercer mundo a hacer un aporte propio en la elaboración de teologías que respondan a los desaflos de sus pueblos. Los elementos comunes pueden llevar a formular una expresión propia que, manteniendo una continuidad con las mejores tradiciones, abra las puertas hacia el tercer mundo.

\section{Sugerencias}

El grupo latinoamericano de EATWOT propone dos puntos concretos a la asamblea general: inicier un proceso de selección y traducción de textos básicos del pensamiento teológico de cada continente para ponerlos al alcance de los otros continentes, y promover el intercambio de profesores visitantes de un continente a otro, para promover el diálogo y el conocimiento de las otras teologias. 